\title{
Mitochondrial differentiation and oxidative phosphorylation system capacity in rat embryo during placentation period
}

\author{
M P Alcolea, B Colom, I Lladó, F J García-Palmer and M Gianotti \\ Grup de Metabolisme Energètic i Nutrició, Departament de Biologia Fonamental i Ciències de la Salut, Institut \\ Universitari d'Investigació en Ciències de la Salut (IUNICS), Universitat de les IIles Balears i CIBER Fisiopatologia \\ Obesidad y Nutrición (CB06/03), Instituto de Salud Carlos III, Spain
}

Correspondence should be addressed to M Gianotti; Email: magdalena.gianotti@uib.es

\begin{abstract}
Mitochondrial biogenesis and function are essential for proper embryo development; however, these processes have not been further studied during the placentation period, when important oxidative metabolism activation is taking place. Thus, the aim of the present study was to investigate the oxidative phosphorylation system (OXPHOS) enzymatic activities as well as the expression of genes involved in the coordinated regulation of both mitochondrial and nuclear genomes (peroxisome proliferatoractivated receptor- $\gamma$ coactivator- $1 \alpha$, nuclear respiratory factors 1 and 2, mitochondrial single-strand DNA-binding protein, mitochondrial transcription factor A), and mitochondrial function (cytochrome $c$ oxidase subunit IV, cytochrome $c$ oxidase subunit I and $\beta$-ATP phosphohydrolase) in rat embryo throughout the placentation period (gestational days 11, 12 and 13). Our results reflect that embryo mitochondria were enhancing their OXPHOS potential capacities, pointing out that embryo mitochondria become more differentiated during the placentation period. Besides, the current findings show that the mRNAs of the nuclear genes involved in mitochondrial biogenesis were downregulated, whereas their protein content together with the mitochondrial DNA expression were upregulated throughout the period studied. These data indicate that the molecular regulation of the mitochondrial differentiation process during placentation involves a post-transcriptional activation of the nuclear-encoded genes that would lead to an increase in both the nuclear- and mitochondrial-encoded proteins responsible for the mitochondrial biogenic process. As a result, embryo mitochondria would reach a more differentiated stage with a more efficient oxidative metabolism that would facilitate the important embryo growth during the second half of the pregnancy.

Reproduction (2007) 134 147-154
\end{abstract}

\section{Introduction}

Mitochondria are cellular organelles that contain their own genetic system, nevertheless, the mitochondrial DNA capacity is very limited ( $\sim 16.5 \mathrm{~kb}$; Clayton 2000, Fernandez-Silva et al. 2003). As a result, the large majority of mitochondrial proteins involved in oxidative functions and biosynthetic capacity, as well as in transcription, translation and replication of mitochondrial DNA (mtDNA) must be encoded by the nuclear genome (Garesse \& Vallejo 2001, Fernandez-Silva et al. 2003). This fact implies the need for strict regulation to coordinate the gene expression of both nuclear and mitochondrial genomes by diverse nuclear transcriptional activators and coactivators (Scarpulla 2006).

Alterations in mitochondrial function and biogenesis have been involved in several human degenerative diseases (Wallace 1999). Thus, research on mitochondrial biogenesis is of great interest, since it would provide the knowledge to understand the pathophysiology of mitochondrial diseases. Numerous protein factors have been reported to be involved in mitochondrial biogenesis in mammals so far, contributing insight into the molecular pathways taking part in this biological process. In short, the family of peroxisome proliferator-activated receptor- $\gamma$ coactivator- $1 \alpha$ (PGC-1 $\alpha$ ) coactivates different transcription factors in response to energy requirements (Scarpulla 2006). Among these transcription factors, nuclear respiratory factors 1 and 2 (NRF-1 and NRF-2) regulate the expression of most nuclear genes involved in mitochondrial biogenesis, such as genes encoding subunits of respiratory complexes, mitochondrial transcription factors $\mathrm{A}, \mathrm{B} 1$ and B2 (TFAM, TFB1M and TFB2M respectively), mitochondrial replication factors like mitochondrial single-strand DNA-binding protein (mtSSB) and mitochondrial RNA-processing endoribonuclease (RNase MRP), as well as other proteins necessary for mitochondrial function (Virbasius \& Scarpulla 1994, Gleyzer et al. 2005, Scarpulla 2006). 
Mitochondriogenesis is a complex event, including both mitochondrial proliferation and differentiation processes (Izquierdo et al. 1995, Ostronoff et al. 1996), which takes place according to specific energy demands in response to several physiological conditions (Williams et al. 1987, Pillar \& Seitz 1997), including prenatal (May-Panloup et al. 2005, Thundathil et al. 2005) and postnatal developmental stages (Luis et al. 1993, Izquierdo et al. 1995, Ostronoff et al. 1996). In middle pregnancy, rat embryo mitochondria undergo considerable morphofunctional changes (Mackler et al. 1973, Shepard et al. 1998, Yang et al. 1998) coinciding with the switch from glycolytic to oxidative metabolism that takes place on gestational day 12 (Akazawa et al. 1994, Shepard et al. 1997), just when the placentary circulation is established and oxygen becomes more available to the embryo (Jollie 1986, Akazawa 2005). In addition, a previous study in our laboratory reported the activation of mitochondrial gene expression throughout the placentation period, suggesting that mitochondrial biogenesis is an active process in rat embryo during this developmental stage (Alcolea et al. 2006). Therefore, embryo development during the placentation period is a suitable model to further understand the mitochondrial proliferation and differentiation processes (Justo et al. 2002).

In light of this background, the aim of the present work was to study the oxidative phosphorylation system (OXPHOS) enzymatic activities in rat embryo throughout gestational days 11, 12 and 13, when placentation takes place (Jollie 1986, Akazawa 2005), to determine whether the changes seen in mitochondrial gene expression were translated into an activation of the mitochondrial respiratory and phosphorylative capacities. Furthermore, we investigated the expression of genes involved in the coordinated transcriptional regulation of both nuclear and mitochondrial genomes (PGC- $1 \alpha$, NRF-1, NRF- $2 \alpha$ and TFAM; Gaspari et al. 2004, Scarpulla 2006), as well as genes related to mitochondrial replication (mtSSB; Hoke et al. 1990), and function, such as cytochrome $c$ oxidase subunit IV, cytochrome $c$ oxidase subunit I and $\beta$-ATP phosphohydrolase (COX IV, COX I and $\beta$-ATPase; Hatefi 1985) to go further into the knowledge of the molecular regulation of rat embryo mitochondrial biogenesis during the placentation period.

\section{Materials and Methods}

\section{Materials}

All enzymes, substrates and coenzymes were obtained from Sigma-Aldrich. Routine chemicals were supplied by Sigma-Aldrich, Roche Diagnostics, Bio-Rad, Merck KGaA, Panreac (Barcelona, Spain) and Pronadisa (Madrid, Spain).
Oligonucleotide primer sequences were from Roche Diagnostics. Chemicals for mRNA RT were obtained from Applied Biosystems (Foster City, CA, USA). Lightcycler-FastStart DNA Master SYBR Green I for real-time PCR and oligonucleotide primer sequences were supplied by Roche Diagnostics.

Antibodies for COX IV were obtained from MitoSciences (MS407; Eugene, Oregon, USA), antibodies for $\beta$-ATPase were from Santa Cruz Biotechnology Inc. (sc16690; Santa Cruz, CA, USA) and rabbit antisera against TFAM was kindly provided by Inagaki et al. (2000). Chemicals for immunoblot development were provided by Amersham.

\begin{abstract}
Animals
Animal experiments were performed in accordance with general guidelines approved by our institutional ethics committee and the EU (86/609/EEC) regulations. Threemonth-old virgin female Wistar rats, purchased from Charles River (Barcelona, Spain), were housed at $22{ }^{\circ} \mathrm{C}$ with a ratio of $12 \mathrm{~h}$ light: $12 \mathrm{~h}$ darkness cycle (lights on at $0800 \mathrm{~h}$ ) with free access to tap water and pelleted standard diet (Panlab, Barcelona, Spain). The females were mated overnight with males of the same strain and, when spermpositive vaginal smears were found the following morning (reference point for gestational day 0 ), they were placed in individual cages.
\end{abstract}

\section{Sacrifice and isolation of samples}

Pregnant rats were killed by decapitation on gestational days 11,12 or 13 . Uteri were removed and between one and three conceptuses (embryos with intact amniotic and yolk sacs) per mother were dissected into a sterile culture dish with physiological saline solution which contained $0.1 \%(\mathrm{v} / \mathrm{v})$ diethyl pyrocarbonate (DEPC) to inactivate RNase activity. The embryos obtained were immediately frozen in liquid nitrogen and stored at $-70{ }^{\circ} \mathrm{C}$ for their subsequent RNA extraction.

The remaining conceptuses were dissected without DEPC added to saline solution. The embryos were rapidly pooled into preweight Eppendorf tubes, which were spun down to remove the remaining saline solution and weighed to determine the average embryo weight. Then, the embryos were homogenised in isolation buffer (300 mM sucrose, $5 \mathrm{mM}$ 4-morpholine propanesulfonic acid (MOPS), $5 \mathrm{mM} \mathrm{KH} \mathrm{PO}_{4}, 1 \mathrm{mM}$ EDTA and $0.01 \%$ BSA (pH 7.4)) and used for mitochondrial isolation. Seven independent experiments were performed, in each of which three to four rats were used on day 11 , two to three on day 12 and one to two on day 13 in order to pool large enough samples to be able to perform all measurements. The total number of rats used was 22 on day 11,15 on day 12 and 10 on day 13 , which 
contributed a total of 219 embryos on day 11, 163 embryos on day 12 and 117 embryos on day 13 .

\section{Isolation of mitochondria}

The mitochondrial fraction was obtained according to Justo et al. (2002). In brief, nuclei and cell debris were first removed using a refrigerated centrifuge (Sigma$3 \mathrm{~K} 30$ ) at $700 \mathrm{~g}$ for $10 \mathrm{~min}$ at $4{ }^{\circ} \mathrm{C}$. The resulting supernatant was subjected to 10-min centrifugation at $1000 \mathrm{~g}$ rendering the mitochondrial fraction to be studied. The pellets were resuspended in the isolation buffer. An aliquot of both homogenate and isolated mitochondria were used to determine cytochrome $c$ oxidase activity and the recovery percentage of the isolated mitochondria was calculated. The remaining samples were frozen at $-70{ }^{\circ} \mathrm{C}$ for subsequent analysis.

Total protein content was measured in both homogenate and mitochondrial fractions (Lowry et al. 1951). Total DNA content was tested in homogenate samples (Thomas \& Farquhar 1978).

\section{OXPHOS enzymatic activities}

OXPHOS enzymatic activities were measured in the mitochondrial fraction using a microtitre plate spectrophotometer (BioTek Instruments, Winooski, VT, USA).

$\mathrm{NADH}$ dehydrogenase (NADH:ubiquinone oxidoreductase, complex I, EC 1.6.5.3) and ATPase (complex $\mathrm{V}$, EC 3.6.1.3) activities were assessed using an adaptation based on a spectrophotometric method (Ragan et al. 1987). The activities were measured at $37^{\circ} \mathrm{C}$ and were calculated using an extinction coefficient of $6.81 \mathrm{mM} / \mathrm{cm}$ for complex I and of $6.22 \mathrm{mM} / \mathrm{cm}$ for ATPase.

Ubiquinol cytochrome $c$ reductase (ubiquinol:ferricytochrome $c$ oxidoreductase, complex III, EC 1.10.2.2) activity was determined using a spectrophotometric assay (Krahenbuhl et al. 1991). In brief, isolated mitochondria were incubated with $0.1 \mathrm{mM}$ EDTA, $0.1 \%$ BSA $(\mathrm{w} / \mathrm{v})$, $150 \mu \mathrm{M}$ cytochrome $c, 3 \mathrm{mM}$ sodium azide and $50 \mathrm{mM}$ potassium phosphate ( $\mathrm{pH} 7.4$ ) in a final volume of $210 \mu \mathrm{l}$. After a 5-min equilibration period, the reactions were started by adding $100 \mu \mathrm{M}$ reduced coenzyme $\mathrm{Q}_{2}$, and the increase in absorbance was monitored at $550 \mathrm{~nm}$. Activities were calculated using an extinction coefficient of $19.1 \mathrm{mM} / \mathrm{cm}$ for reduced cytochrome $c$. Antimycin A-sensitive activities were obtained by subtraction of the rate determined in incubations containing $10 \mu \mathrm{g}$ antimycin A from the rate in parallel with antimycin A-free incubations. Reduced coenzyme $\mathrm{Q}_{2}$ was synthesised according to Ragan et al. (1987).

Cytochrome $c$ oxidase (ferrocytochrome $c$ : oxygen oxidoreductase, COX, EC 1.9.3.1) activity was determined by a spectrophotometric method (Chrzanowska-Lightowlers et al. 1993) following the oxidation of $3,3^{\prime}$ diaminobenzidine-tetrahydrochloride at $450 \mathrm{~nm}$ and $37^{\circ} \mathrm{C}$.

\section{mtDNA extraction and semi-quantification}

mtDNA extraction and semi-quantification were carried out in isolated mitochondria as previously described (Justo et al. 2002). The extracted mtDNA was quantified by real-time PCR using SYBR Green technology on a LightCycler rapid thermal cycler (Roche Diagnostics). PCR was performed to amplify a 162 nt region of the mitochondrial NADH dehydrogenase subunit 4 gene. The primer sequences were $5^{\prime}$-TACACGATGAGGCAACCAAA- $3^{\prime}$ and $5^{\prime}$-GGTAGGGGGTGTGTTGTGAG- ${ }^{\prime}$.

\section{Real-time RT-PCR analysis}

Total RNA was isolated from frozen embryo samples using TriPure isolation reagent and quantified using a spectrophotometer set at $260 \mathrm{~nm}$.

Total RNA $(1 \mu \mathrm{g})$ was reverse transcribed to CDNA at $42{ }^{\circ} \mathrm{C}$ for 60 min with $25 \mathrm{U}$ MuLV reverse transcriptase in a $10 \mu \mathrm{l}$ retrotranscription reaction mixture containing $10 \mathrm{mM}$ Tris- $\mathrm{HCl}(\mathrm{pH} 9.0), 50 \mathrm{mM} \mathrm{KCl}, 0.1 \%$ Triton $\mathrm{X}-100,2.5 \mathrm{mM} \mathrm{MgCl} 2,2.5 \mu \mathrm{M}$ random hexamers, $10 \mathrm{U}$ RNase inhibitor and $500 \mu \mathrm{M}$ of each dNTP. Each cDNA was diluted $1 / 10$ and aliquots were frozen $\left(-70^{\circ} \mathrm{C}\right)$ until the PCRs were carried out.

Real-time PCR was carried out for seven target genes: PGC- $1 \alpha$; NRF-1 and NRF-2 DNA-binding $\alpha$ subunit, $\mathrm{mtSSB}$, TFAM, COX IV and COX I; and one

Table 1 Oligonucleotide primer sequences used in real-time PCR amplification.

\begin{tabular}{|c|c|c|c|c|c|}
\hline Gene & GenBank number & Forward primer $\left(5^{\prime}-3^{\prime}\right)$ & Reverse primer $\left(5^{\prime}-3^{\prime}\right)$ & Product length $(\mathrm{bp})$ & $T_{\mathrm{m}}$ \\
\hline PGC-1 $\alpha$ & NM_031347 & ATG TGT CGC CTT CTT GCT CT & ATC TAC TGC CTG GGG ACC TT & 179 & 84.6 \\
\hline NRF-1 & XM_231566 & TTA CTC TGC TGT GGC TGA TGG & ССТ CTG ATG CTT GCG TCG TCT & 87 & 85.2 \\
\hline NRF- $2 \alpha$ & XM_344002 & CAG AGC AAG TGA CGA GAT GG & CCG AAA TGT TGA GTG TGG TG & 176 & 87.2 \\
\hline $\mathrm{mtSSB}$ & M94557 & GCG TCA GGA AAA GCC TAA AG & TCG CCA CAT CTC ATT TGT TG & 243 & 84.3 \\
\hline TFAM & AJ312746 & GCT AAA CAC CCA GAT GCA AAA & CGA GGT CTT TTT GGT TTT CC & 269 & 84.1 \\
\hline COX IV & X15029 & TGG GAG TGT TGT GAA GAG TGA & GCA GTG AAG CCG ATG AAG AAC & 272 & 89.1 \\
\hline COX I & X14848 & AGC AGG AAT AGT AGG GAC AGC & TGA GAG AAG TAG TAG GAC GGC & 520 & 84.3 \\
\hline $18 \mathrm{~S}$ & X01117 & GAG GTG AAA TTC TTG GAC CGG & CGA ACC TCC GAC TTT CGT TCT & 93 & 83.6 \\
\hline
\end{tabular}

PGC-1 $\alpha$, peroxisome proliferator-activated receptor- $\gamma$ coactivator $1 \alpha$; NRF-1, nuclear respiratory factor 1 ; NRF- $2 \alpha$, nuclear respiratory factor 2 DNA-binding $\alpha$ subunit; mtSSB, mitochondrial single-strand DNA-binding protein; TFAM, mitochondrial transcription factor A; COX IV, cytochrome c oxidase subunit IV; COX I, cytochrome $c$ oxidase subunit I; 18S, 18S rRNA. 
housekeeping gene: 18S rRNA (18S). All oligonucleotide primer sequences were obtained from primer 3 and tested with IDT OligoAnalyzer 3.0 (NCBl; Table 1). Finally, a basic local alignment search tool (NCBI BLAST) revealed that the primer sequence homology was obtained only for the target genes.

Real-time PCR was performed as previously described (Alcolea et al. 2006). The amplification programme consisted of a preincubation step for denaturation of the template cDNA $\left(10 \mathrm{~min}\right.$ at $\left.95^{\circ} \mathrm{C}\right)$, followed by 40 cycles consisting of a denaturation step $\left(10 \mathrm{~s}\right.$ at $\left.95^{\circ} \mathrm{C}\right)$, an annealing step $\left(12 \mathrm{~s}\right.$ at $60{ }^{\circ} \mathrm{C}$ for PGC- $1 \alpha$ and $62{ }^{\circ} \mathrm{C}$ for $18 \mathrm{~S}, 10 \mathrm{~s}$ at $58{ }^{\circ} \mathrm{C}$ for $\mathrm{mtSSB}$ and COX IV at $60^{\circ} \mathrm{C}$ for TFAM and at $64^{\circ} \mathrm{C}$ for NRF- $2 \alpha, 8 \mathrm{~s}$ at $55^{\circ} \mathrm{C}$ for COX I, $5 \mathrm{~s}$ at $56{ }^{\circ} \mathrm{C}$ for NRF-1) and an extension step $\left(12 \mathrm{~s}\right.$ at $72{ }^{\circ} \mathrm{C}$ for all, except for NRF-1 and COX I, which were $8 \mathrm{~s}$ at $72{ }^{\circ} \mathrm{C}$ and $26 \mathrm{~s}$ at $72{ }^{\circ} \mathrm{C}$ respectively). After each cycle, fluorescence was measured at $72{ }^{\circ} \mathrm{C}$. A negative control without cDNA template was run in each assay.

The real-time PCR efficiencies (e) were estimated on average of all sample efficiencies, which were calculated by the following formula

$e=\left(\frac{F}{F_{0}}\right)^{1 / n-n_{0}}$

where $n$ and $n_{0}$ were the crossing point values of $F$ and $F_{0}$ respectively, fluorescences that belong to the linear section of the logarithmic quantification curve.

\section{Western blot analysis}

Equal amounts of mitochondrial protein $(40 \mu \mathrm{g})$ were electrophoresed on SDS-PAGE gels containing 15\% (v/v) polyacrylamide. Proteins were electrotransferred onto a nitrocellulose filter and Ponceau $S$ staining was performed systematically to check the correct loading and electrophoretic transfer. Blots with mitochondrial proteins were incubated with mouse polyclonal antibody for COX IV, goat polyclonal antibody for
$\beta$-ATPase and rabbit antisera against TFAM. Immunoblot development was performed using an ECL Western blotting analysis system. Film bands were quantified by photodensitometric analysis (Kodak 1D Image Analysis Software). The apparent molecular weights of the proteins detected were 14, 51 and $25 \mathrm{kDa}$ for COX IV, $\beta$-ATPase and TFAM respectively.

\section{Statistical analysis}

All data are expressed as mean \pm S.E.M. Differences between gestational days were assessed by one-way ANOVA followed by least significant difference (LSD) post-hoc test using the statistical software package SPSS 13.0 for Windows (SPSS, Chicago, IL, USA).

The statistical PCR data analysis was performed using the Relative Expression Software Tool (REST 2005 BETA V1.9.12). The statistical model used was a pair-wise fixed reallocation randomisation test (Pfaffl et al. 2002, 2004). Differences in expression between groups were assessed using the means for statistical significance by randomisation tests. Results were considered statistically significant at the $P<0.05$ level.

\section{Results}

\section{Embryo weight and composition}

Embryo weight, total protein and DNA (tDNA) content showed a great rise throughout the gestational days studied (11, 12 and 13), whereas the protein and DNA concentration decreased significantly (Table 2). These results reflect that the important growth of the embryo during the placentation period entailed both cellular hypertrophy and hyperplasia processes.

mtDNA content per tDNA showed an important drop throughout the period studied unlike the ratio between mitochondrial protein content and tDNA, which did not change significantly (Table 2). As mtDNA content can be used as an indicator of mitochondrial content (Djouadi

Table 2 Rat embryo weight and composition on gestational days 11, 12 and 13.

\begin{tabular}{|c|c|c|c|c|c|}
\hline & \multirow[b]{2}{*}{$\mathbf{N}$ (mother/embryo) } & \multicolumn{3}{|c|}{ Gestational days } & \multirow[b]{2}{*}{ ANOVA } \\
\hline & & $\begin{array}{c}11 \\
22 / 197\end{array}$ & $\begin{array}{c}12 \\
15 / 148\end{array}$ & $\begin{array}{c}13 \\
10 / 103\end{array}$ & \\
\hline \multicolumn{6}{|l|}{ Embryo } \\
\hline Weight & (mg) & $2.73 \pm 0.16$ & $17.9 \pm 0.4^{*}$ & $54.1 \pm 2.0^{*,+}$ & $\mathrm{D}$ \\
\hline \multirow[t]{2}{*}{ Protein } & (mg/embryo) & $0.280 \pm 0.014$ & $1.32 \pm 0.07^{*}$ & $3.35 \pm 0.21^{*,+}$ & $\mathrm{D}$ \\
\hline & (mg/g embryo) & $97.6 \pm 2.9$ & $73.6 \pm 2.8^{*}$ & $64.2 \pm 1.4^{*,+}$ & $\mathrm{D}$ \\
\hline \multirow[t]{2}{*}{ tDNA } & ( $\mu \mathrm{g} /$ embryo) & $30.0 \pm 1.7$ & $156 \pm 18^{*}$ & $259 \pm 24^{*,+}$ & $\mathrm{D}$ \\
\hline & (mg/g embryo) & $11.2 \pm 0.9$ & $8.71 \pm 1.06$ & $5.03 \pm 0.47^{*,+}$ & $\mathrm{D}$ \\
\hline \multicolumn{6}{|c|}{ Mitochondria } \\
\hline mtDNA & MtDNA/tDNA & $100 \pm 5$ & $40.3 \pm 3.4^{*}$ & $33.4 \pm 3.1^{*}$ & $\mathrm{D}$ \\
\hline Protein & g protein/g tDNA & $0.514 \pm 0.042$ & $0.350 \pm 0.062$ & $0.458 \pm 0.043$ & NS \\
\hline
\end{tabular}

Total protein and DNA (tDNA) were measured in homogenate samples. Mitochondrial protein and DNA (mtDNA) were determined in isolated mitochondria. mtDNA content on day 11 was set as $100 \%$. Data represent the mean \pm s.E.M. of seven independent experiments. One-way ANOVA $(P<0.05)$ : D, gestational day effect. Post-hoc analysis (LSD test; $P<0.05):{ }^{*} P \leq 0.05$ vs $11 ;{ }^{\dagger} P \leq 0.05$ vs 12 . 
et al. 1994, Koekemoer \& Oelofsen 2001), these data are in agreement with a previous work (Alcolea et al. 2006), suggesting a reduction in the number of mitochondria per embryo cell accompanied by an enrichment in the protein content of these mitochondria during the current developmental stage.

\section{Mitochondrial function}

Table 3 shows the enzymatic activities of complex I, III, IV and ATPase measured on gestational days 11, 12 and 13 in isolated mitochondria. All OXPHOS enzymatic activities presented a similar profile, i.e. a rise during the placentation period. Although all OXPHOS activities showed an increasing trend when they were expressed per tDNA and per mitochondrial protein (1.3- to 2.3-fold and 1.0- to 3.9-fold respectively), this profile was statistically significant only for complex III and ATPase. The ratio between OXPHOS activities and mtDNA, however, showed a significant increase in all cases and the rise was higher than those observed per both tDNA and mitochondrial protein (3.6- to 7.1-fold).

\section{Relative mRNA levels of genes involved in mitochondrial biogenesis}

The expression of gene-encoding proteins related to the coordinated transcriptional regulation of both nuclear and mitochondrial genomes (PGC- $1 \alpha, \mathrm{NRF}-1, \mathrm{NRF}-2 \alpha$ and TFAM), mitochondrial replication ( $\mathrm{mtSSB}$ ) and function (COX IV and COX I) is shown in Table 4. The mRNA levels of most of the nuclear-encoded genes studied (NRF-1, NRF-2 $\alpha$, TFAM, mtSSB and COX IV) showed a profile of decrease throughout the placentation period which was statistically significant in all cases except for TFAM, in which a downward trend was observed. Nevertheless, mRNA levels of PGC- $1 \alpha$, which is also a nuclear-encoded gene, did not show significant differences.

Besides, the mRNA levels of COX I, a protein encoded by mtDNA heavy strand, which is transcribed as a polygene rendering 12 out of the $13 \mathrm{mtDNA}$ proteins (Garesse \& Vallejo 2001), showed a statistically significant increase during the placentation period.

\section{Western blot analysis of nuclear-encoded proteins}

The levels of the nuclear-encoded proteins COX IV, $\beta$-ATPase and TFAM are given in Fig. 1. These data showed an increasing profile throughout the period studied, which was statistically significant on gestational day 13 .

\section{Discussion}

The current results indicate that mitochondrial differentiation is an active process in rat embryo throughout the organogenic period, coinciding with a great activation of its oxidative metabolism and important embryonic growth. This mitochondriogenic process seems to be controlled by a post-transcriptional regulation of the nuclear-encoded genes involved in mitochondrial biogenesis, leading to an increase in the nuclear- and mitochondrial-encoded proteins and, hence to a rise in the mitochondrial OXPHOS capacity of the rat embryo during the placentation period, from 11 to 13 days of embryo development.

Rat embryo mitochondria during placentation are a suitable model to further understand mitochondrial biogenesis due to the important oxidative metabolism activation that takes place (Mackler et al. 1971, Akazawa et al. 1994). However, this developmental stage has not been further characterised. Our results show that although embryo cells were decreasing their mitochondria content throughout the placentation period,

Table 3 Rat embryo mitochondrial activities of oxidative phosphorylation system on gestational days 11, 12 and 13.

\begin{tabular}{|c|c|c|c|c|c|}
\hline & \multirow[b]{2}{*}{$\mathbf{N}$ (mother/embryo) } & \multicolumn{3}{|c|}{ Gestational days } & \multirow[b]{2}{*}{ ANOVA } \\
\hline & & $\begin{array}{c}11 \\
22 / 197\end{array}$ & $\begin{array}{c}12 \\
15 / 148\end{array}$ & $\begin{array}{c}13 \\
10 / 103\end{array}$ & \\
\hline \multirow[t]{3}{*}{ Complex I activity } & I.U/g tDNA & $4.72 \pm 0.48$ & $5.92 \pm 1.09$ & $6.00 \pm 0.69$ & NS \\
\hline & $\mathrm{ml} \mathrm{U/mtP}$ & $13.4 \pm 2.6$ & $14.1 \pm 2.8$ & $13.9 \pm 1.3$ & NS \\
\hline & $\% \mathrm{Cl} / \mathrm{mtDNA}$ & $100 \pm 8$ & $319 \pm 71^{*}$ & $363 \pm 38^{*}$ & $\mathrm{D}$ \\
\hline \multirow[t]{3}{*}{ Complex III activity } & I.U/g tDNA & $26.4 \pm 2.3$ & $39.9 \pm 3.6$ & $61.8 \pm 8.8^{*,+}$ & $\mathrm{D}$ \\
\hline & $\mathrm{ml} \mathrm{U/mtP}$ & $47.9 \pm 5.0$ & $139 \pm 7 *$ & $185 \pm 35^{*}$ & $\mathrm{D}$ \\
\hline & $\%$ CIII/mtDNA & $100 \pm 11$ & $378 \pm 31^{*}$ & $712 \pm 40^{*,+}$ & $\mathrm{D}$ \\
\hline \multirow[t]{3}{*}{ Complex IV activity } & $\%$ CIV/tDNA & $100 \pm 5$ & $105 \pm 15$ & $125 \pm 15$ & NS \\
\hline & $\% \mathrm{CIV} / \mathrm{mtP}$ & $100 \pm 12$ & $142 \pm 32$ & $152 \pm 16$ & NS \\
\hline & $\% \mathrm{CIV} / \mathrm{mtDNA}$ & $100 \pm 8$ & $302 \pm 42 *$ & $418 \pm 54^{*}$ & $\mathrm{D}$ \\
\hline \multirow[t]{3}{*}{ ATPase activity } & I.U/g tDNA & $20.4 \pm 3.4$ & $17.2 \pm 2.1$ & $40.2 \pm 4.5^{*,+}$ & $\mathrm{D}$ \\
\hline & $\mathrm{ml} U / \mathrm{mtP}$ & $36.8 \pm 2.8$ & $60.8 \pm 3.3^{*}$ & $85.6 \pm 5.0^{*,+}$ & $\mathrm{D}$ \\
\hline & $\%$ ATPase/mtDNA & $100 \pm 17$ & $212 \pm 28^{*}$ & $582 \pm 42^{*,+}$ & $\mathrm{D}$ \\
\hline
\end{tabular}

Data represent the mean \pm S.E.M. of seven independent experiments. The values on day 11 of complex IV activity and activities per mitochondrial DNA (mtDNA) were set as $100 \%$ expressing the other two days as a percentage. tDNA, total DNA; mtP, mitochondrial protein. One-way ANOVA $(P<0.05)$ : D, gestational day effect. Post-hoc analysis (LSD test; $P<0.05):{ }^{*} P \leq 0.05$ vs $11 ;{ }^{\dagger} P \leq 0.05$ vs 12 . 
Table 4 Rat embryo mRNA levels of genes involved in mitochondrial biogenesis and function on gestational days 11,12 and 13.

\begin{tabular}{|c|c|c|c|c|c|}
\hline & \multicolumn{4}{|c|}{ Gestational days } & \multirow[b]{3}{*}{ REST } \\
\hline & \multicolumn{2}{|c|}{12} & \multicolumn{2}{|c|}{13} & \\
\hline & Expression & REST.Error & Expression & REST.Error & \\
\hline PGC- $1 \alpha$ & 0.766 & $0.539-1.35$ & 1.07 & $0.594-2.07$ & NS \\
\hline NRF-1 & 1.00 & $0.828-1.19$ & $0.538^{*,+}$ & $0.450-0.628$ & $P \leq 0.05$ \\
\hline NRF- $2 \alpha$ & 1.18 & $0.859-1.57$ & $0.629^{*},+$ & $0.464-0.896$ & $P \leq 0.05$ \\
\hline TFAM & 0.690 & $0.369-1.25$ & 0.598 & 0.350-1.10 & NS \\
\hline $\mathrm{mtSSB}$ & $0.598^{*}$ & $0.446-0.781$ & $0.420^{*}$ & $0.271-0.605$ & $P \leq 0.05$ \\
\hline COX IV & 1.01 & $0.840-1.21$ & $0.722 *$ & $0.595-0.903$ & $P \leq 0.05$ \\
\hline COX I & 0.713 & $0.427-1.07$ & $2.03 *,+$ & $1.31-3.11$ & $P \leq 0.05$ \\
\hline $18 \mathrm{~S}$ & 0.992 & $0.723-1.54$ & 0.865 & $0.641-1.19$ & NS \\
\hline
\end{tabular}

Values on day 11 were set as 1 . Data represent the mean expression of seven independent experiments, $N$ (mothers/embryos) $=22 / 22$ on day 11 ,

$15 / 15$ on day 12 and $10 / 14$ on day 13 . The statistical model used was a pair-wise fixed reallocation randomisation test $(P<0.05): * P \leq 0.05$ vs 11 ;

${ }^{+} P \leq 0.05$ vs 12 .

as suggested by the mtDNA content, they were actually increasing their OXPHOS capacities. Furthermore, the rise seen in the OXPHOS enzymatic activities when expressed per mtDNA reflect that each embryo mitochondrion was increasing its potential respiratory capacity. All these results suggest that a mitochondrial differentiation process would predominate over mitochondrial proliferation in rat embryo throughout the placentation period, increasing the mitochondrial efficiency in order to face the important energy demands of this developmental stage.

For the purpose of going further into the knowledge of the molecular regulation of rat embryo mitochondrial differentiation during the placentation period, we studied the factors involved in the coordinated regulation of the nuclear and mitochondrial genomes since they both take part in mitochondriogenesis (Shadel \& Clayton 1997, Fernandez-Silva et al. 2003). This orchestrated process is a complex event carried out by nuclear transcriptional activators and coactivators that modulate the expression of nuclear genes encoding the necessary proteins for maintenance, replication and expression of mtDNA, as well as for most OXPHOS subunits and other mitochondrial proteins (Kelly \& Scarpulla 2004). The downward trend shown by most genes encoded at a nuclear level (NRF-1, NRF-2 $\alpha$, TFAM, mtSSB and COX IV) reflected that the PGC- $1 \alpha$ pathway, by which this coactivator together with NRFs regulate the expression of several nuclear genes involved in mitochondrial biogenesis, among which TFAM, $\mathrm{mtSSB}$ and COX IV are found (Virbasius \& Scarpulla 1994, Kelly \& Scarpulla 2004), would be reduced. Nevertheless, the increasing profile observed in the protein content of some nuclear-encoded proteins, such as COX IV, $\beta$-ATPase as well as TFAM, indicates that the regulation of the expression of the nuclear-encoded proteins related to the mitochondriogenic process was taking place at a post-transcriptional level, in such a way that despite the reduction of the transcription their protein content would increase leading to a mitochondrial differentiation process.

The lack of correlation observed between the mRNA levels of the nuclear genes encoding proteins involved in mitochondrial biogenesis and the protein content of some of them reflects that the mitochondrial biogenic process together with the concomitant activation of the respective molecular pathways would have started very early during development, maybe during the preimplantation period as previously described in mouse and bovine embryos (May-Panloup et al. 2005, Thundathil et al. 2005). As a result, during the gestational days studied in the current work, the nuclear transcriptional signals involved in mitochondrial biogenesis could already be reduced and other post-transcriptional signals, such as increased mRNA stability and/or translational efficiency, would become available to keep the mitochondrial differentiation process active. Therefore, such regulation would be similar to what has previously been reported during the rat perinatal period (Luis et al. 1993, Izquierdo et al. 1995, Ostronoff et al. 1996).

Besides, during the placentation period, embryo mitochondria showed a significant increase in TFAM content, which as one of the regulatory factors necessary for proper mtDNA transcription (Montoya et al. 1997, Larsson et al. 1998, Garstka et al. 2003, Gaspari et al. 2004) could cause the significant rise seen in the mRNA expression of COX I, a protein encoded by the mtDNA heavy strand. Taking into account that the transcription of all the mRNAs encoded by the mtDNA heavy strand originates a polycistronic molecule (Garesse \& Vallejo 2001, Fernandez-Silva et al. 2003), the current results reflect an increase in the gene expression of the mitochondrial proteins encoded by this strand, i.e. the majority of the mitochondrial-encoded proteins. Thus, the aforementioned increase in the nuclear-encoded proteins, such as TFAM, would lead to an activation of the mtDNA transcription and all together would help the embryo mitochondria to reach a more differentiated stage through a coordinate regulation of both nuclear 
COX IV

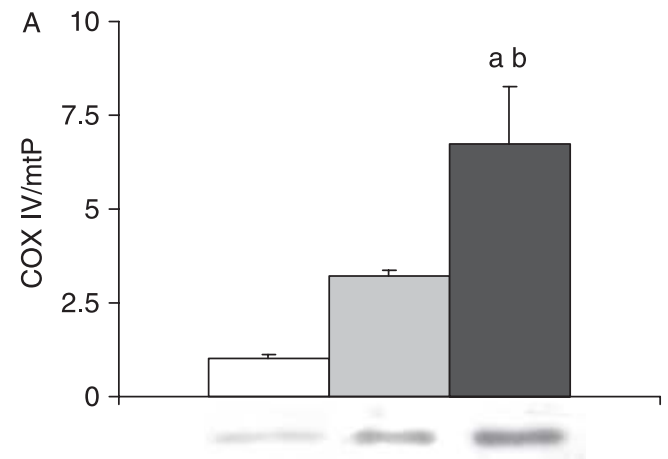

Beta-ATPase



TFAM

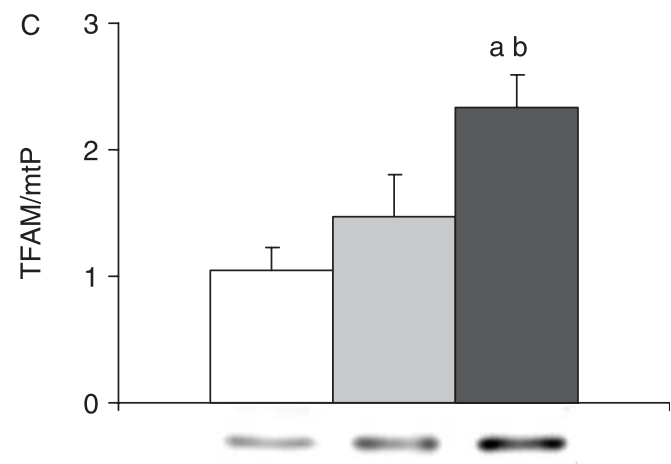

Gestational days $11 \square \quad 12 \square 13 \square$

Figure 1 Rat embryo mitochondrial COX IV (cytochrome $c$ oxidase subunit IV), $\beta$-ATPase (F1-ATPase $\beta$ subunit) and TFAM (mitochondrial transcription factor $\mathrm{A}$ ) protein content during placentation period. Data represent the mean \pm s.E.M. of seven independent experiments, $N$ (mothers/embryos) $=22 / 197$ on day $11,15 / 148$ on day 12 and $10 / 103$ on day 13 . Values on day 11 were set as $1 . \mathrm{mtP}$, mitochondrial protein. One-way ANOVA $(P<0.05)$ : D, gestational day effect. Post-hoc analysis (LSD test; $P<0.05):{ }^{\mathrm{a}} P \leq 0.05$ vs $11 ;{ }^{\mathrm{b}} P \leq 0.05$ vs 12 .

and mitochondrial-encoded proteins. This idea corroborates the activation of the mitochondrial differentiation process in rat embryo during the placentation period that we have previously suggested (Alcolea et al. 2006).

In conclusion, throughout the placentation period, rat embryo mitochondria would be undergoing a mitochondrial differentiation process involving an increase in OXPHOS potential enzymatic activities. The molecular regulation of this mitochondrial process throughout this developmental stage would be carried out through a post-transcriptional activation of nuclearencoded proteins involved in the mitochondriogenic pathway. This activation would, among others, provide most OXPHOS subunits as well as regulatory proteins that would activate the expression of the mtDNA, which encodes the catalytic core subunits of these enzymes. This, all in all, would lead to an increased OXPHOS capacity and would, thus, prepare the embryo to use the oxidisable metabolites now available from the newly established chorioallantoic circulation.

\section{Acknowledgements}

We are grateful to Hidetoshi Inagaki, PhD from National Industrial Research Institute of Nagoya (Japan), for kindly providing the rabbit antisera against mitochondrial transcription factor A protein. M P Alcolea and B Colom were funded by grants of the 'Ministerio de Educación Cultura y Deporte' of Spanish Government. This investigation was supported by 'Fondo de Investigaciones Sanitarias' (PI042294 and PI042377) of the 'Instituto de Salud Carlos III' of the Spanish Government. The authors declare that there is no conflict of interest that would prejudice the impartiality of this scientific work.

\section{References}

Akazawa S 2005 Diabetic embryopathy: studies using a rat embryo culture system and an animal model. Congenital Anomalies $\mathbf{4 5}$ 73-79.

Akazawa S, Unterman T \& Metzger BE 1994 Glucose metabolism in separated embryos and investing membranes during organogenesis in the rat. Metabolism 43 830-835.

Alcolea MP, Colom B, Llado I, Gianotti M \& Garcia-Palmer FJ 2006 Mitochondrial transcription factor A (TFAM) is increased in rat embryo during placentation and associated with mitochondrial differentiation. Cellular Physiology and Biochemistry 17 79-88.

Chrzanowska-Lightowlers ZM, Turnbull DM \& Lightowlers RN 1993 A microtiter plate assay for cytochrome $c$ oxidase in permeabilized whole cells. Analytical Biochemistry 214 45-49.

Clayton DA 2000 Vertebrate mitochondrial DNA - a circle of surprises. Experimental Cell Research 255 4-9.

Djouadi F, Bastin J, Gilbert T, Rotig A, Rustin P \& Merlet-Benichou C 1994 Mitochondrial biogenesis and development of respiratory chain enzymes in kidney cells: role of glucocorticoids. American Journal of Physiology 267 C245-C254.

Fernandez-Silva P, Enriquez JA \& Montoya J 2003 Replication and transcription of mammalian mitochondrial DNA. Experimental Physiology 88 41-56.

Garesse R \& Vallejo CG 2001 Animal mitochondrial biogenesis and function: a regulatory cross-talk between two genomes. Gene $\mathbf{2 6 3}$ $1-16$.

Garstka HL, Schmitt WE, Schultz J, SogI B, Silakowski B, PerezMartos A, Montoya J \& Wiesner RJ 2003 Import of mitochondrial transcription factor A (TFAM) into rat liver mitochondria stimulates transcription of mitochondrial DNA. Nucleic Acids Research 31 5039-5047. 
Gaspari M, Falkenberg M, Larsson NG \& Gustafsson CM 2004 The mitochondrial RNA polymerase contributes critically to promoter specificity in mammalian cells. EMBO Journal 23 4606-4614.

Gleyzer N, Vercauteren K \& Scarpulla RC 2005 Control of mitochondrial transcription specificity factors (TFB1M and TFB2M) by nuclear respiratory factors (NRF-1 and NRF-2) and PGC- 1 family coactivators. Molecular and Cellular Biology 25 1354-1366.

Hatefi Y 1985 The mitochondrial electron transport and oxidative phosphorylation system. Annual Review of Biochemistry $\mathbf{5 4}$ 1015-1069.

Hoke GD, Pavco PA, Ledwith BJ \& Van Tuyle GC 1990 Structural and functional studies of the rat mitochondrial single strand DNA binding protein P16. Archives of Biochemistry and Biophysics 282 116-124.

Inagaki H, Hayashi T, Matsushima Y, Lin KH, Maeda S, Ichihara S, Kitagawa Y \& Saito T 2000 Isolation of rat mitochondrial transcription factor A (r-Tfam) cDNA. DNA Sequence 11 131-135.

Izquierdo JM, Ricart J, Ostronoff LK, Egea G \& Cuezva JM 1995 Changing patterns of transcriptional and post-transcriptional control of $\beta$-F1-ATPase gene expression during mitochondrial biogenesis in liver. Journal of Biological Chemistry 270 10342-10350.

Jollie WP 1986 Ultrastructural studies of protein transfer across rodent yolk sac. Placenta $7263-281$.

Justo R, Alcolea MP, Colom B, Riera AN, Gianotti M \& GarciaPalmer FJ 2002 Morphofunctional changes in the mitochondrial subpopulations of conceptus tissues during the placentation process. Cellular and Molecular Life Sciences 59 2199-2209.

Kelly DP \& Scarpulla RC 2004 Transcriptional regulatory circuits controlling mitochondrial biogenesis and function. Genes and Development 18 357-368.

Koekemoer TC \& Oelofsen W 2001 Properties of porcine white adipose tissue and liver mitochondrial subpopulations. International Journal of Biochemistry and Cell Biology 33 889-901.

Krahenbuhl S, Chang M, Brass EP \& Hoppel CL 1991 Decreased activities of ubiquinol:ferricytochrome coxidoreductase (complex III) and ferrocytochrome c:oxygen oxidoreductase (complex IV) in liver mitochondria from rats with hydroxycobalamin[c-lactam]-induced methylmalonic aciduria. Journal of Biological Chemistry 266 20998-21003.

Larsson NG, Wang J, Wilhelmsson H, Oldfors A, Rustin P, Lewandoski M, Barsh GS \& Clayton DA 1998 Mitochondrial transcription factor A is necessary for mtDNA maintenance and embryogenesis in mice. Nature Genetics 18 231-236.

Lowry OH, Rosebrough NJ, Farr AL \& Randall RJ 1951 Protein measurement with the Folin phenol reagent. Journal of Biological Chemistry 193 265-275.

Luis AM, Izquierdo JM, Ostronoff LK, Salinas M, Santaren JF \& Cuezva JM 1993 Translational regulation of mitochondrial differentiation in neonatal rat liver. Specific increase in the translational efficiency of the nuclear-encoded mitochondrial beta-F1-ATPase mRNA. Journal of Biological Chemistry 268 1868-1875.

Mackler B, Grace R \& Duncan HM 1971 Studies of mitochondrial development during embryogenesis in the rat. Archives of Biochemistry and Biophysics 144 603-610.

Mackler B, Grace R, Haynes B, Bargman GJ \& Shepard TH 1973 Studies of mitochondrial energy systems during embryogenesis in the rat. Archives of Biochemistry and Biophysics 158 662-666.

May-Panloup P, Vignon X, Chretien MF, Heyman Y, Tamassia M, Malthiery Y \& Reynier P 2005 Increase of mitochondrial DNA content and transcripts in early bovine embryogenesis associated with upregulation of mtTFA and NRF1 transcription factors. Reproductive Biology and Endocrinology 365.
Montoya J, Perez-Martos A, Garstka HL \& Wiesner RJ 1997 Regulation of mitochondrial transcription by mitochondrial transcription factor A. Molecular and Cellular Biochemistry 174 227-230.

Ostronoff LK, Izquierdo JM, Enriquez JA, Montoya J \& Cuezva JM 1996 Transient activation of mitochondrial translation regulates the expression of the mitochondrial genome during mammalian mitochondrial differentiation. Biochemical Journal 316 183-191.

Pfaffl MW, Horgan GW \& Dempfle L 2002 Relative expression software tool (REST) for group-wise comparison and statistical analysis of relative expression results in real-time PCR. Nucleic Acids Research 30 e36.

Pfaffl MW, Tichopad A, Prgomet C \& Neuvians TP 2004 Determination of stable housekeeping genes, differentially regulated target genes and sample integrity: BestKeeper - excel-based tool using pair-wise correlations. Biotechnology Letters 26 509-515.

Pillar TM \& Seitz HJ 1997 Thyroid hormone and gene expression in the regulation of mitochondrial respiratory function. European Journal of Endocrinology 136 231-239.

Ragan Cl, Wilson MT, Darley-Usmar VM \& Lowe PN 1987 Subfractionation of mitochondria and isolation of the proteins of oxidative phosphorilation. In Mitochondria, A Practical Approach, pp 79-112. Eds VM Darley-Usmar, D Rickwood \& MT Wilson. Oxford: IRL Press.

Scarpulla RC 2006 Nuclear control of respiratory gene expression in mammalian cells. Journal of Cellular Biochemistry 97 673-683.

Shadel GS \& Clayton DA 1997 Mitochondrial DNA maintenance in vertebrates. Annual Review of Biochemistry 66 409-435.

Shepard TH, Tanimura T \& Park HW 1997 Glucose absorption and utilization by rat embryos. International Journal of Developmental Biology 41 307-314.

Shepard TH, Muffley LA \& Smith LT 1998 Ultrastructural study of mitochondria and their cristae in embryonic rats and primate $(N$. nemistrina). Anatomical Record 252 383-392.

Thomas PS \& Farquhar MN 1978 Specific measurement of DNA in nuclei and nucleic acids using diaminobenzoic acid. Analytical Biochemistry 89 35-44.

Thundathil J, Filion F \& Smith LC 2005 Molecular control of mitochondrial function in preimplantation mouse embryos. Molecular Reproduction and Development 71 405-413.

Virbasius JV \& Scarpulla RC 1994 Activation of the human mitochondrial transcription factor A gene by nuclear respiratory factors: a potential regulatory link between nuclear and mitochondrial gene expression in organelle biogenesis. PNAS 91 1309-1313.

Wallace DC 1999 Mitochondrial diseases in man and mouse. Science 283 1482-1488.

Williams RS, Garcia-Moll M, Mellor J, Salmons S \& Harlan W 1987 Adaptation of skeletal muscle to increased contractile activity. Expression nuclear genes encoding mitochondrial proteins. Journal of Biological Chemistry 262 2764-2767.

Yang X, Borg LA \& Eriksson UJ 1998 Metabolic alteration in neural tissue of rat embryos exposed to beta-hydroxybutyrate during organogenesis. Life Sciences 62 293-300.

Received 8 January 2007

First decision 6 February 2007

Accepted 15 March 2007 